\title{
Identidade em questão - memórias médicas da escola de medicina da Bahia: ficção ou história?
}

Kédima Ferreira de Oliveira Matos Mestre em História da Ciência - PUC-SP; Doutoranda em Ensino e História da Ciência - Unicamp; Professora do Departamento de Química - Uniban. São Paulo - SP [Brasil] kedima@ige.unicamp.br

Nailton Santos de Matos Mestre em Literatura e Crítica Literária - PUC-SP; Professor do Departamento de Educação nos cursos de Letras e de Pedagogia - Uninove. São Paulo - SP [Brasil] nailtonmatos@yahoo.com
Desde Aristóteles, história e ficção se avizinham, embora os compromissos de uma e de outra sejam distintos. Este trabalho propõe um debate em torno dos limites tênues entre história e ficção, discutindo os desafios teóricos e metodológicos para a criação de paradigmas de interpretação da realidade. As memórias médicas da Faculdade de Medicina da Bahia se configuram como narrativas que põem em xeque os limites entre História e Literatura. Produzidas nos séculos XIX e XX e narradas por professores catedráticos dessa universidade, as memórias aparecem como narrativas que possibilitam ponderar sobre a relatividade da "verdade" nelas encontrada, uma vez que são construídas com base na subjetividade. A realidade narrada é organizada pela memória do sujeito historiador que a transforma em texto. Nesse processo, o historiador se aproxima do literato que também busca, na matéria desordenada do real, atribuir sentido aos fatos.

Palavras-chave: Ficção. História e literatura. Memória. 


\section{Introdução}

Tanto em Platão (1965) quanto em Aristóteles (1966), a arte é ficção, pois difere do real. Nesse contexto, a ficção, não sendo realidade, é uma criação da imaginação, da fantasia. Assim, a essência da ficção literária encontra-se na expressão "parecer como realidade". A ficção, ou seja, a literatura cria a ilusão da vida que, por sua vez, é gerada na arte por um ser ou um "eu" vivo, que sente, pensa e fala. Nessas condições, o discurso literário, também denominado de discurso de representação, caracteriza-se sob o rótulo de ficção, pois objetiva o representar de forma diferente daquele do cotidiano. Dessa forma, o autor de ficção aborda os fatos primários, derivados diretamente da realidade, mas sob um ângulo diferente. $\mathrm{O}$ romancista permanece livre para representar todo e qualquer acontecimento como modelo de uma história do mundo, da sociedade, do homem e de si mesmo.

Segundo Vavy Pacheco Borges (1984), o termo história contém dois significados: acontecimento (é a história do homem visto como um ser social, vivendo em sociedade) e conhecimento (fazer entender as condições da realidade, tendo em vista o delineamento da atuação do homem na própria História). Desse modo, por meio da História, é possível entender as transformações pelas quais as sociedades humanas passaram, uma vez que é pelo tempo que se percebem essas mudanças, pois nada permanece igual.

Conforme Paul Veyne (1983), cabe ao historiador, assim como ao ficcionista, provar, argumentar, defender algum tipo de tese. O historiador tem como função dar um testemunho de uma História, transmitindo-a com base em fatos e documentos. Sua matéria-prima é o real. Utiliza a terceira pessoa gramatical, registrando os eventos o mais afastado possível. O discurso histórico relata, em linguagem denotativa, unívoca e monológica, o que aconteceu a pessoas com identidade civil, utilizando, como fontes de informações, documentos, relatos e manuscritos.

Apesar das diferenças entre literatura e história, muitos ficcionistas se apropriaram da temática histórica, fazendo surgir um conjunto de obras que mostram a História muito além de um momento idealizado, convertendo-a em instrumento de análise de um passado que se abre para explicar o presente e projetar o futuro. No texto histórico e, de modo mais específico, na escritura memorialista, é possível perceber elementos presentes na composição de textos ficcionais.

O diálogo que, por meio deste trabalho, buscase estabelecer entre a História e a ficção indica duas situações: a) projetar a escritura memorialista na ficção; b) discutir o papel das fontes da historiografia.

É possível admitir uma diferença e, ao mesmo tempo, uma afinidade entre os dois campos. A afinidade encontra-se no fato de que ambos narram uma realidade; a diferença é que o historiador trabalha com elementos que "se supõe" sejam verdadeiros, com acontecimentos reais, e o romancista vale-se de acontecimentos fictícios, mas que funcionam como se fossem reais. Assim, se não há certeza de que os fatos relatados pela História sejam verdades, a literatura e a História recorrem aos mesmos elementos.

\section{Memórias médicas da Escola de Medicina da Bahia}

As memórias históricas da Escola de Medicina eram relatos anuais feitos pelos professores, escolhidos pela congregação, que deveriam apresentar, na primeira sessão do ano seguinte, a memória dos acontecimentos do ano letivo passado. 
As memórias surgiram do desejo de refletir sobre os acontecimentos ocorridos a cada ano na Faculdade de Medicina, assim como para promover o desenvolvimento científico.

Havendo-vos lembrado, sem que eu saiba porque, do meu obscuro nome para commetter-me o encargo de escrever a Memória histórica da nossa Faculdade concernente ao anno de 1924, tenho a honra deapresentar-vos o trabalho que, no cumprimento do vosso mandato me permitiram fazer as minhas apoucadas força e habilitações. (ARAGÃO, 1940, p. 7).

A construção de uma narrativa memorialista põe-nos diante da fragilidade da realidade histórica. Os fatos, nela contidos, são produto da subjetividade. Nessa perspectiva, os eventos reconstruídos pela memória do historiador são por ele reorganizados e ressignificados. Nesse processo, o historiador se aproxima do literato, pois, a seu modo, também não deixa de inventar.

Testemunhando-vos, antes de tudo, os meus sinceros agradecimentos pela prova de confiança com que, por vossa nímia benevolência, vos dignastes distinguir-me, e a que muito receio não ter podido corresponder, - supplico a vossa indulgência para os defeitos e as lacunas de que sou primeiro a reconhecer se recente a minha modéstia obra: defeitos fataes, porque resultantes das deficiências do autor; lacunas, porém, que em grande parte poderiam deixar de existir, si me não houvessem faltado muitas das informações, - necessárias à evitação de taes falhas - informações que pedi a todos os illustrados Collegas que compõem o corpo docente deste Instituto, mas de poucos tive a satisfação de recebellas. (ARAGÃO, 1940, p. 7).

A memória seria formada por decisões do sujeito, tomadas ao longo do tempo, para conferir ordem às suas ações.

Ao expor o pensamento bachelardiano, Carvalho da Rocha e Eckert (2001) apresentam, com bastante perspicácia, toda a complexidade da memória como resultado de escolhas de fatos da vida, nos quais o sujeito põe seus sentidos. Demonstram ainda que o passado superpõe-se ao presente, de forma ritmada, resultando em uma "hierarquia de instantes" que dá forma à "dialética da duração".

Nesse sentido, somos todos compositores de nosso próprio passado, pois o ato de recordar, que é uma intenção do presente, se faz por meio de imagens que se originam das razões do sujeito.

Gonçalo Moniz Sodré de Aragão, responsável pela memória histórica da Faculdade de Medicina da Bahia relativa ao ano de 1924, tem plena consciência da complexidade de construção de uma narrativa memorialista.

Bem sei, porém, e justamente porque nem todos vêem e julgam da mesma forma e com a mesma exactidão os objectos e os acontecimentos do mundo exterior, - que cada um de nós pode errar ou illudir-se na maior boa fé. Essa disparidade das apreciações e dos conceitos humanos, embora formados muitas vezes com toda a sinceridade, pelas próprias testemunhas imparciaes dos factos a que aqueles se referem, já se acha assignalada pela philosophia 
tradicional no conhecido proloquio - tot capita, tot sententiae. (1940, p. 8).

A memória e a experiência atuam ativamente na extensão temporal que permanecerá no presente: as vagas noções de "antes" e de "depois", de "anterior" e de "posterior" se aglutinam na experiência do presente e marcam a ordem e a direção do tempo. É necessário que se observe que essa ordenação não é objetiva, porque, na memória, o tempo se funde e se sobrepõe ao presente, o que torna essa ordenação vaga e ambígua em razão dos mecanismos psicológicos como reprimir, distorcer, esquecer ou projetar.

A etimologia da memória expressa tanto o fato da recordação, lembranças, reminiscências quanto o ato de narrar, referir, relatar. A memória é a memória e seu avesso. Ela não é apenas a lembrança, uma faculdade psíquica, ela é também, a um só tempo, a lembrança e seu relato. A narrativa do que é memorado.

O historiador Le Goff (1994, p. 423) vê a memória como um conjunto de funções psíquicas que possibilitam ao homem conservar certas informações e atualizar impressões ou informações passadas. Além da capacidade de capturar o passado no presente, a memória também opera o registro do presente para que permaneça como lembrança, capaz de ser acionada. Essa lembrança é composta pelo arquivo de coisas que selecionamos, o que nos põe diante da constatação de que existem critérios que operam a seletividade da memória. Como o fazemos? Que parâmetros operam as escolhas? Quais são as diferenças que existem de um indivíduo para outro?

A procura de respostas para essas outras questões vem suscitando muitos debates e encontra hoje lugar assegurado nos fóruns acadêmicos. Por outro lado, como reação às acusações de ser esse um País sem memória, em que o esquecimento é a vala comum de episódios e personagens, atores e ações, a comunidade intelectual busca preservar a memória.

Uma das preocupações básicas no resgate da memória é descobrir como as condições históricas gerais são apropriadas, reelaboradas e vivenciadas pelas pessoas das mais diversas inserções sociais. $\mathrm{O}$ entrecruzamento de diversas falas permite reconstituir o tecido social, em toda a sua complexidade, incorporando a multiplicidade de significados e revelando as determinações estruturais e simbólicas que fornecem sentido às práticas sociais.

Octávio Torres, outro memorialista da Faculdade de Medicina, vê a verdade histórica como uma construção resultante do cruzamento de diversas fontes históricas. A narrativa impõe limitações à sua própria escritura, uma vez que as estruturas e indivíduos envolvidos revelam multiplicidade de sentidos.

Procurei, ainda, com o maior patriotismo, com justiça e imparcialidade compatíveis com espírito humano, descrever todos os fatos e as individualidades que neles tomam parte, com a maior fidelidade, dentro da verdade histórica, baseado nos documentos existentes nos Arquivos e nas narrativas e tradições dos nossos maiores e que chegaram ao meu conhecimento. (TORRES, 1946, p. 8).

Há momentos em que o historiador precisa preencher lacunas da realidade pesquisada, e o faz por meio da ficção. É ficção, mas poderia ter acontecido. É uma interpretação com base em documentos.

Embora operem em contextos "diferentes", a ficção e a história buscam a verdade por caminhos diferentes, mediadas pela subjetividade e pelas experiências do sujeito. 
O valor de qualquer exposição historica sobe de ponto, ao meu juízo, se fôr acompanhada da critica judiciosa, de commentarios opportunos sobre as occorrencias descriptas, fazendo-se comparações elucidativas dos factos referidos com outros analogos acontecidos em lugares e tempos diferentes, investigando-se-lhes o determinismo, traçando-se-lhes a evolução assignalando-se as transformações por que hão passado nos successivos periodos do decorrer das eras. (ARAGÃO, 1940, p. 514).

Um historiador não se prende apenas a fatos, mas usa-os a serviço da construção do texto. A organização dos fatos e sua compreensão pelo sujeito levam-nos a questionar os limites da história e da ficção.

Gonçalo de Aragão deixa bem claro que, mesmo fazendo uso de fatos e documentos, o historiador se põe como intérprete da realidade, o que o impossibilita de se portar com neutralidade diante dos fatos.

Para Hayden White, há ligação entre história e ficção, principalmente no que se refere à neutralidade do documento. Ao propor um compromisso com a inteligibilidade de um tema, que, em seus estudos, chamou de urdidura de enredo, o historiador não dependeria apenas da escrita objetiva para se fazer entendido. Ele afirma que

O modo como uma determinada situação histórica deve ser configurada depende da sutileza com que o historiador harmoniza a estrutura específica de enredo com o conjunto de acontecimentos históricos aos quais deseja conferir um sentido particular. (WHITE, 1994, p. 102).
Segundo White, o historiador deveria incorporar em seu trabalho modelos de análise e de construção literárias. Para ele,

[...] tem havido uma relutância em considerar as narrativas históricas como o que elas mais manifestamente são: ficções verbais, cujos conteúdos são tão inventados como descobertos, e cujas formas têm mais em comum com suas contrapartidas na literatura que na ciência. (1994, p. 82).

\section{Considerações finais}

Não é objetivo deste trabalho destituir o valor do discurso memorialista, mas identificar que, em sua narrativa, o historiador lança mão de elementos literários, filosóficos e científicos. Ao utilizar esse tipo de narrativa, o sujeito recolhe e interpreta fatos organizados com base na experiência do historiador. Tal qual na ficção, o sujeito está impregnado de subjetividade. Entretanto, isso não invalida seu discurso, que, por meio desses elementos, pode-nos oferecer uma visão mais totalizante da realidade.

Segundo Pedro Brum Santos, muitos historiadores têm " [...] sugerido que a historiografia deve utilizar-se das variações e criatividades que podem ser constatadas nos diversos níveis da narrativa literária. Desse modo, incorporaria no próprio discurso o caráter inerente relativo a todo conhecimento sobre o passado." (1996, p. 19).

A questão da representação da realidade tem suscitado discussões no círculo daqueles que vêm trabalhando com a escrita da história. Ficção e história possuem pontos de vista contraditórios, mas convergentes. Ambas constituem formas legítimas de conhecimento da realidade. Outra questão rele- 
vante diz respeito à natureza do conhecimento produzido pela pesquisa do historiador diante dos novos estudos: arte ou ciência, ficção ou história? Qual a sua identidade?

\section{Identity in question - medical memories of the school of medicine of Bahia: fiction or history?}

Since Aristotle, history and fiction dialogue, although the commitments of both are otherwise distinct. This paper proposes a debate about the unstable limits between history and fiction, discussing the theoretical and methodological challenges of the creation of paradigms for the interpretation of reality. Medical memories of the school of medicine of Bahia is configured as narratives that question the limits between history and literature. Produced in the XIX and XX centuries and narrated by professors of the university, the memories appear as narratives that allow considering the relativity of "truth" found in them, since they are built on subjectivity. The reality that is narrated is organized by the memory of the historian, which transforms it in text. In this case, the historian is putted together with the writer that, in a disordered field of the real, also attempts to give meaning to the facts.

Key words: Fiction. History and literature. Memory.

\section{Referências}

ARAGÃO, G. M. S. Memória histórica da Faculdade de Medicina da Babia: relativa ao anno de 1924. Salvador: UFBA, 1940.

ARISTÓTELES. Poética. Porto Alegre: Globo, 1966.

BORGES, V. P. O que é história. São Paulo: Brasiliense, 1984.

CARVALHO DA ROCHA, A. M.; ECKERT, C. Imagens do tempo nos meandros da memória, In: Imagem e memória, ensaios em antropologia visual. Rio de Janeiro: Gramond, 2001.

LE GOFF, J. História e memória. 3.ed. Campinas, São Paulo: Editora da Unicamp, 1994.

PLATÃO. A República. São Paulo: Difusão Européia do Livro, 1965.

SANTOS, P. B. Teorias do romance: relações entre ficção e história. Santa Maria: UFSM, 1996.

TORRES, O. Esboço histórico dos acontecimentos mais importantes da vida da Faculdade de Medicina da Babia. Salvador: Imprensa Vitória, 1946.

VEYNE, P. Como se escreve a história. Lisboa: Edições 70, 1983.

WHITE, H. O texto histórico como artefato literário. In: Trópicos do discurso: ensaios sobre a crítica da cultura. São Paulo: EDUSP, 1994.

recebido em 30 mar. 2009 / aprovado em 13 ago. 2009

Para referenciar este texto:

MATOS, K. F. de O.; MATOS, N. S. de. Identidade em questão: memórias médicas da escola de medicina da Bahia: ficção ou história? Dialogia, São Paulo, v. 8 , n. 2, p. 243-248, 2009.

Dialogia, São Paulo, v. 8, n. 2, p. 243-248, 2009. 